\title{
Three-Dimensional Speckle Tracking Echocardiography Allows Detailed Evaluation of Left Atrial Function in Hypertrophic Cardiomyopathy- Insights from the MAGYAR-Path Study
}

\author{
Péter Domsik, M.D., Anita Kalapos, M.D., Számi Chadaide, M.D., Róbert Sepp, M.D., Ph.D., \\ Péter Hausinger, M.D., Tamás Forster, M.D., Ph.D., D.Sc., F.E.S.C., F.A.C.C., and \\ Attila Nemes, M.D., Ph.D., F.E.S.C.
}

2nd Department of Medicine and Cardiology Center, Medical Faculty, Albert Szent-Györgyi Clinical Center, University of Szeged, Szeged, Hungary

Introduction: Hypertrophic cardiomyopathy (HCM) represents a generalized myopathic process affecting both ventricular and atrial myocardium. Reduced left atrial (LA) function was demonstrated in HCM by different methods. Three-dimensional (3D) speckle tracking echocardiography (STE) has just been introduced for the evaluation of LA. This study was designed to compare 3DSTE-derived LA volumetric and strain parameters in HCM with healthy controls. Methods: The study comprised 23 consecutive HCM patients (mean age: $48.5 \pm 15.1$ years, 14 men). Their results were compared to 23 age- and gender-matched healthy controls. Complete two-dimensional Doppler echocardiography and 3DSTE have been performed in all cases. Results: Calculated LA maximum (66.4 $\pm 20.4 \mathrm{~mL}$ vs. 36.0 $\pm 6.1 \mathrm{~mL}, \mathrm{P}<0.0001)$ and minimum (39.2 \pm 19.1 vs. $16.0 \pm 4.6 \mathrm{~mL}, \mathrm{P}<0.0001)$ volumes and LA volume before atrial contraction (53.6 \pm 19.9 vs. $24.0 \pm 6.2 \mathrm{~mL}, \mathrm{P}<0.0001)$ were significantly increased in HCM patients. Atrial stroke volumes respecting cardiac cycles proved to be increased, while emptying fractions were decreased in subjects with HCM. Mean global radial $(-12.2 \pm 6.7 \%$ vs. $-19.6 \pm 11.7, \mathrm{P}<0.05)$, longitudinal $(26.5 \pm 16.5 \%$ vs. $29.8 \pm 12.1 \%, \mathrm{P}<0.05)$ and $3 \mathrm{D}$ strain $(-6.1 \pm 4.4 \%$ vs. $-12.5 \pm 10.2 \%, \mathrm{P}<0.05)$ proved to be significantly reduced in HCM patients as compared with matched controls. Conclusions: Three-dimensional speckle tracking echocardiography allows detailed evaluation of LA (dys) function in HCM by volumetric and strain measurements. (Echocardiography 2014;31:1245-1252)

Key words: echocardiography, function, hypertrophic cardiomyopathy, left atrium, three-dimensional, speckle tracking

Hypertrophic cardiomyopathy (HCM) is a complex, relatively common genetic cardiac disease that is heterogeneous with respect to gene mutations, clinical symptoms, prognosis, and treatment strategies. ${ }^{1}$ HCM represents a generalized myopathic process affecting both ventricular and atrial myocardium. ${ }^{2}$ Most of the patients are in steady condition, although HCM is known as one of the most common cause of sudden death in juvenile patients. ${ }^{1}$ HCM is characterized by excessive asymmetric left ventricular (LV) hypertrophy involving primarily the interventricular septum. ${ }^{1}$ It

Address for correspondence and reprint requests: Attila Nemes, M.D., Ph.D., F.E.S.C., 2nd Department of Medicine and Cardiology Center, Medical Faculty, Albert Szent-Györgyi Clinical Center, University of Szeged, H-6720 Szeged, Korányi fasor 6, Hungary, P.O. Box 427. Fax: 36-62-544568;

E-mail: nemes.attila@med.u-szeged.hu is known that diastolic LV dysfunction is more common in HCM than systolic dysfunction. Due to reduced ventricular compliance and impaired relaxation, elevated left atrial (LA) and pulmonary vascular pressures are known complications in $\mathrm{HCM}^{3}$ Due to sensitivity of thin-walled LA to volume and pressure changes, increased LV load pressure could lead to LA dilation which is known to be associated with increased morbidity and mortality in HCM. ${ }^{4}$ Enlarged LA volume was found to be associated with impaired functional NYHA class and shows inverse correlation with treadmill exercise capacity in $\mathrm{HCM}^{5}$ P-wave duration combined with LA antero-posterior diameter and myocardial deformation indices resulted in a higher power for discriminating HCM patients with paroxysmal atrial fibrillation. ${ }^{6}$ All these studies should draw our attention to the importance of 
accurate evaluation of LA volumes and function respecting cardiac cycle in $\mathrm{HCM}^{6}{ }^{6}$ Changes could be demonstrated in all three components of LA function in HCM: in the phase of reservoir component or expansion during systole, in conduit phase during diastole and in active contractile phase during late diastole.

Several clinical noninvasive tools have been demonstrated to be useful for assessment of LA function in HCM. Three-dimensional (3D) speckle tracking echocardiography (STE) seems to be a promising tool for accurate evaluation of global and regional cardiac function. ${ }^{8}$ 3DSTE has just been introduced for the evaluation of LA. ${ }^{9-12}$ This study was designed to measure and compare 3DSTE-derived LA volumetric and strain parameters in HCM and healthy matched controls.

\section{Patients and Methods:}

\section{Patient Population:}

A total of 23 patients with typical features of $\mathrm{HCM}$ were included in this study. The diagnosis of HCM was confirmed in all patients according to the guidelines. ${ }^{13}$ In all cases, hypertrophy was asymmetrical and had septal localization. HCM was known for several years in these patients, and $75 \%$ of the cases were genetically analyzed with genotype/mutation analysis. Their results were compared to 23 age- and gender-matched healthy controls. All healthy subjects with known diseases which could affect the results were excluded from the control group. Complete twodimensional (2D) Doppler echocardiography and 3DSTE have been performed in all HCM cases and controls. Diabetes mellitus (DM) was defined in accordance with the American Diabetes Association and World Health Organization criteria. Hypertension was defined as either a systolic or a diastolic elevation of the blood pressure $(>140 /$ $90 \mathrm{mmHg}$ ) or ongoing antihypertensive therapy. Hypercholesterolemia was defined as a total cholesterol level $>5.0 \mathrm{mmol} / \mathrm{L}$ or current treatment with lipid-lowering medications. All subjects have been included in the MAGYAR-Path Study (Motion Analysis of the heart and Great vessels bY three-dimensionAl speckle tRacking echocardiography in Pathological cases). This has been organized at the Cardiology Center of the University of Szeged, Hungary to evaluate usefulness, diagnostic and prognostic value of 3DSTEderived volumetric, strain, rotational etc. parameters in pathological cases ("magyar" means in Hungarian language "Hungarian"). Informed consent was obtained from each patient and the study protocol conformed to the ethical guidelines of the 1975 Declaration of Helsinki, as reflected in a priori approval by the institution's human research committee. ${ }^{14}$
Two-Dimensional Echocardiography:

Complete 2D Doppler echocardiographic examinations were performed in all cases. Standard 2D echocardiographic studies were carried out with a commercially available Toshiba Artida echocardiography equipment (Toshiba Medical Systems, Tokyo, Japan) with a PST-30SBP (1-5 MHz) phased array transducer. LV dimensions, volumes and ejection fraction, and LA dimension were measured in parasternal long-axis view by Teichholz method in all cases. Color Doppler echocardiography was used to visually quantify degree of mitral regurgitation (MR).

\section{DSTE Volumetric Measurements:}

All patients underwent 3D echocardiographic acquisitions immediately following 2D echocardiographic study using a commercially available PST-25SX matrix-array transducer (Toshiba Medical Systems) with 3DSTE capability. ${ }^{9-12}$ Within a single breath-hold and during a constant RR interval, 6 wedge-shaped subvolumes were acquired from an apical window to create fullvolume 3D datasets. The sector width was decreased as much as possible to improve temporal and spatial resolution of the image to obtain a full-volume dataset of LA with optimal border delineation. Chamber quantification by 3DSTE was performed offline using 3D WallMotion Tracking software version 2.5 (Toshiba Medical Systems). 3D echocardiographic datasets were displayed in apical four-chamber (AP4CH) and two-chamber (AP2CH) views and 3 short-axis views in basal, midatrial, and superior $\mathrm{LA}$ regions, respectively (Fig. 1). In the $\mathrm{AP} 4 \mathrm{CH}$ and AP2CH views, the endocardial border was traced by setting multiple reference points by the user starting at base of the LA at mitral valve level going toward the LA apex and excluding the LA appendage and pulmonary veins from the LA cavity (Fig. 1). The epicardial border was adjusted manually or by setting a default thickness for the myocardium. After detection of the LA borders at the end-diastolic reference frame 3D wall-motion tracking, which is based on 3D block-matching algorithm, was automatically performed by the software. The user could correct the shape of the LA if needed throughout the entire cardiac cycle.

The following volumetric calculations have been performed $^{15}$ :

(1) Maximum volume $\left(V_{\max }\right)$ at end-systole, the time at which atrial volume was largest just before mitral valve opening,

(2) Minimum volume $\left(\mathrm{V}_{\min }\right)$ : at end-diastole, the time at which atrial volume is at its nadir before mitral valve closure, 


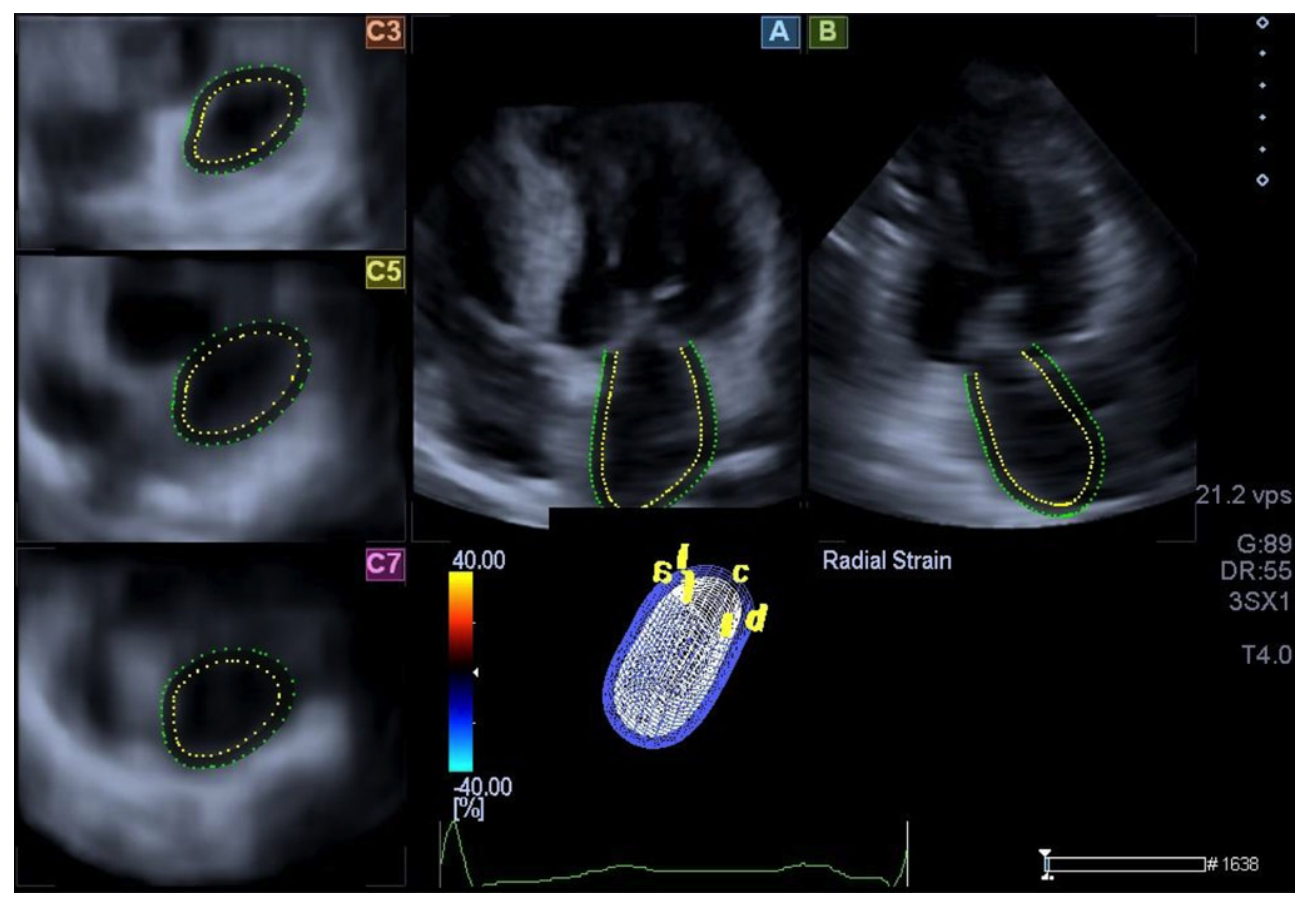

Figure 1. Images from three-dimensional full-volume dataset showing left atrium in a patient with hypertrophic cardiomyopathy: A. apical four-chamber view, B. apical two-chamber view, C3. parasternal short-axis view at basal, C5. mid- and C7. superior left atrial level. The semiautomated left atrial border definition and three-dimensional "wire" reconstruction of the left atrium based on three-dimensional speckle tracking echocardiographic analysis are also presented.

(3) Volume before atrial contraction $\left(V_{\text {preA }}\right)$ : the last frame before mitral valve reopening or at the time of P-wave on ECG.

From the three volumes several parameters characterizing each phase of LA function could be assessed (see Table I).

\section{DSTE Strain Measurements:}

The following strain parameters were routinely measured by the software in a semiautomatic fashion from the 3D echocardiographic dataset: longitudinal strain (LS) in the direction tangential to the endocardial contour, circumferential strain (CS) in circumferential direction, and radial strain (RS) in perpendicular direction to the endocardial contour. Besides these "unidimensional" parame- ters, novel strain parameters using 3D wallmotion tracking were also recorded, such as 3D strain (3DS) defined as strain in the direction of wall thickening and area strain (AS) as a ratio of endocardial area change during the cardiac cycle. $^{10,11}$ Examples of time-strain curves generated by the software are given in Figure 2 .

\section{Statistical Analysis:}

All data are reported as mean \pm standard deviation. $A$ value of $P<0.05$ was considered to be statistically significant. Independent samples Student's t-test were used to compare continuous variables and chi-square test to compare categorical ones. MedCalc software was used for statistical calculations (MedCalc, Mariakerke, Belgium).

TABLE I

The Way to Calculate Left Atrial Stroke Volumes and Emptying Fractions in Each Phase of Left Atrial Motion

\begin{tabular}{lll}
\hline Functions & Stroke Volumes $(\mathrm{mL})$ & Emptying Fractions (\%) \\
\hline Reservoir & Total SV $=\mathrm{V}_{\max }-\mathrm{V}_{\min }$ & Total EF $=$ Total SV/V $\mathrm{V}_{\max }$ \\
Conduit function & Passive $\mathrm{SV}=\mathrm{V}_{\max }-\mathrm{V}_{\text {preA }}$ & Passive EF $=$ Passive $S V / V_{\max }$ \\
Active contraction & Active $S V=\mathrm{V}_{\text {preA }}-\mathrm{V}_{\min }$ & Active EF $=$ Active $S V / V_{\text {preA }}$ \\
\hline
\end{tabular}

$\mathrm{EF}=$ emptying fraction; $\mathrm{SV}=$ stroke volume; $\mathrm{V}_{\max }=$ maximum left atrial volume; $\mathrm{V}_{\min }=$ minimum left atrial volume; $\mathrm{V}_{\text {preA }}=$ left atrial volume before left atrial contraction. 

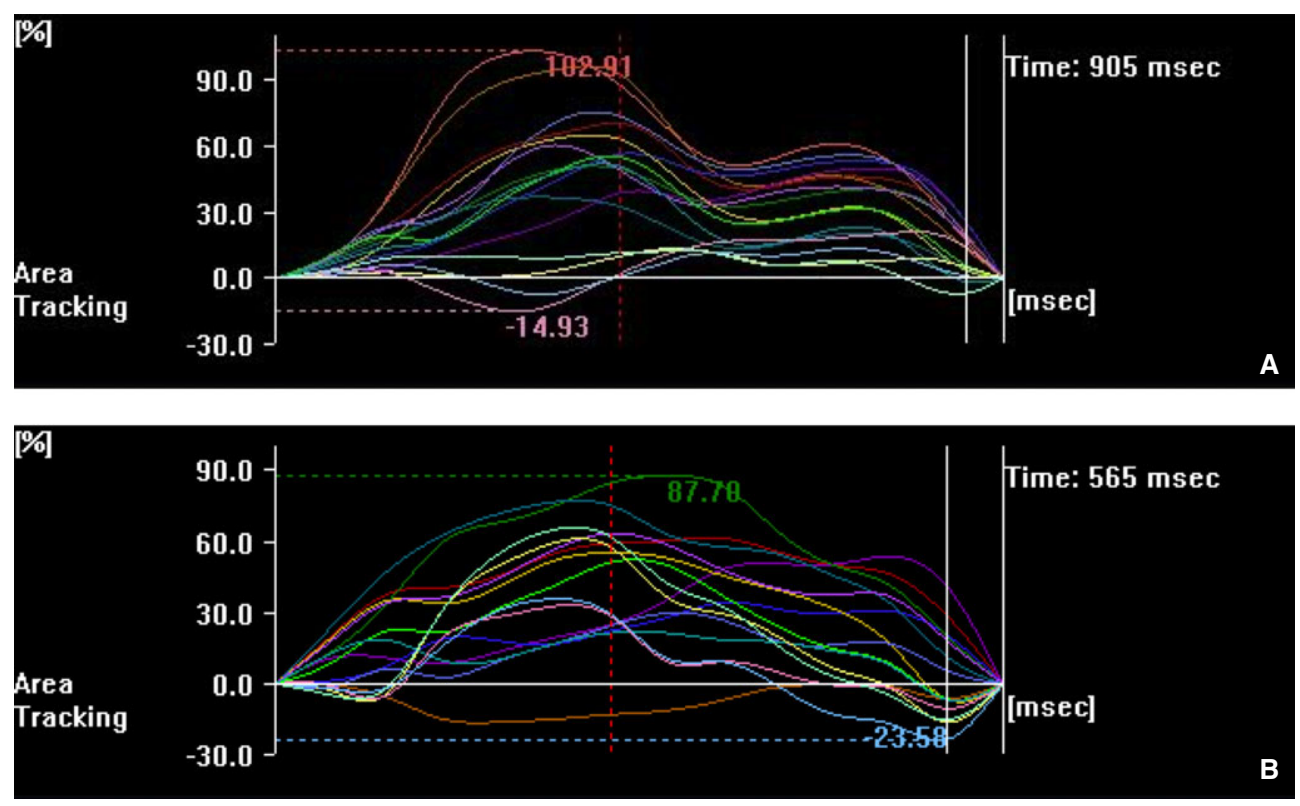

Figure 2. Examples of time-strain curves of 16 left atrial segments in a healthy control subject A. and in a patient with hypertrophic cardiomyopathy $\mathbf{B}$.

\section{Results:}

\section{Clinical Characteristics:}

Classic cardiovascular risk factors and medications of HCM patients and controls are presented in Table II. Eleven of $23 \mathrm{HCM}$ patients had significant $(>30 \mathrm{mmHg}$ ) resting peak LV outflow tract gradient (mean: $69.5 \pm 30.1 \mathrm{mmHg}$ ), whereas $15 \mathrm{HCM}$ patients had systolic anterior motion of the anterior leaflet of the mitral valve. Other 3 HCM patients had implantable cardiac defibrillator due to prophylaxis of malignant arrhythmia and $1 \mathrm{HCM}$ patient had biological prosthetic valve in aortic position. One HCM patient had former percutaneous transluminal septal myocardial ablation.

\section{Two-Dimensional Echocardiographic Data:}

Standard 2D echocardiographic data are summarized in Table II. Significant ( $\geq$ grade 2 ) MR could be detected in 9 HCM patients (39\%). LV endsystolic diameter was significantly decreased, while interventricular septum was significantly increased in HCM patients (Table II).

\section{Three-Dimensional Speckle Tracking Echocardiographic Data:}

Significantly increased LA volumes respecting heart cycle could be detected in HCM patients. Total and active atrial stroke volumes (TASV and AASV) were significantly increased, whereas total and passive atrial emptying fractions (TAEF and PAEF) were significantly decreased in patients with HCM (Table III). Global and mean segmental strain parameters proved to be reduced in
HCM patients as compared to controls (Table IV). There were no differences between HCM patients with versus without hypertension and/or DM in this patient population in both LA volumetric and strain functional properties. Calculated LA volumes were significantly larger in HCM patients with MR $\geq 2$ versus cases with MR $<2$, only TAEF showed significant difference from calculated parameters. There were no differences between $\mathrm{HCM}$ patients with $\mathrm{MR} \geq 2$ versus $\mathrm{MR}<2$ in strain parameters.

\section{Discussion:}

To the best of the authors' knowledge, this is the first study in which increased LA volumes and total and active LA stroke volumes could be demonstrated in patients with HCM by 3DSTE. Moreover, total and passive LA emptying fractions proved to be significantly decreased. 3DSTEderived strain parameters were also reduced in HCM patients as compared with matched controls. These data could draw our attention to the fact that 3DSTE enables more detailed evaluation of LA dysfunction including detection of volumetric changes respecting its motion during heart cycle, even in HCM. Moreover, evaluation of different strains at the same time seems to be a quantitative way to demonstrate LA functional abnormalities.

Several noninvasive imaging methods including M-mode and 2D Doppler echocardiography, ${ }^{16,17}$ 2DSTE, ${ }^{18}$ tissue Doppler imaging (TDI), ${ }^{18}$ volumetric real time 3D echocardiography (RT3DE), ${ }^{9,15}$ cine computed tomography 


\section{TABLE II}

Clinical and Two-Dimensional Echocardiographic Characteristics of Hypertrophic Cardiomyopathy Patients and Controls

\begin{tabular}{|c|c|c|}
\hline & $\begin{array}{l}\text { HCM patients } \\
\quad(\mathrm{n}=23)\end{array}$ & $\begin{array}{l}\text { Controls } \\
(n=23)\end{array}$ \\
\hline \multicolumn{3}{|l|}{ Risk factors } \\
\hline Age (years) & $48.5 \pm 15.1$ & $41.0 \pm 11.8$ \\
\hline Male gender (\%) & $14(61)$ & $13(57)$ \\
\hline $\begin{array}{l}\text { Body mass index } \\
\left(\mathrm{kg} / \mathrm{m}^{2}\right)\end{array}$ & $27.4 \pm 5.0$ & $25.3 \pm 3.5$ \\
\hline Diabetes mellitus (\%) & $10(44)^{*}$ & $0(0)$ \\
\hline Hypertension (\%) & $11(48)^{*}$ & $0(0)$ \\
\hline $\begin{array}{l}\text { Hypercholesterolemia } \\
(\%)\end{array}$ & $2(9)^{*}$ & $0(0)$ \\
\hline \multicolumn{3}{|l|}{ Medications } \\
\hline$\beta$-blockers (\%) & $20(87)^{*}$ & $0(0)$ \\
\hline ACE-inhibitors (\%) & $8(35)^{*}$ & $0(0)$ \\
\hline Diuretics (\%) & $8(35)^{*}$ & $0(0)$ \\
\hline \multicolumn{3}{|c|}{ Two-dimensional echocardiography } \\
\hline LA diameter (mm) & $46.2 \pm 5.2^{\dagger}$ & $33.8 \pm 3.9$ \\
\hline $\begin{array}{l}\text { LV end-diastolic } \\
\text { diameter }(\mathrm{mm})\end{array}$ & $45.1 \pm 3.9$ & $46.3 \pm 5.1$ \\
\hline $\begin{array}{l}\text { LV end-diastolic } \\
\text { volume }(\mathrm{ml})\end{array}$ & $95.5 \pm 23.4$ & $100.2 \pm 26.8$ \\
\hline $\begin{array}{l}\text { LV end-systolic } \\
\text { diameter (mm) }\end{array}$ & $27.3 \pm 4.8^{*}$ & $31.2 \pm 4.9$ \\
\hline $\begin{array}{l}\text { LV end-systolic } \\
\text { volume }(\mathrm{ml})\end{array}$ & $29.9 \pm 13.1$ & $37.9 \pm 15.2$ \\
\hline $\begin{array}{l}\text { Interventricular } \\
\text { septum }(\mathrm{mm})\end{array}$ & $22.8 \pm 5.6^{\dagger}$ & $9.2 \pm 2.1$ \\
\hline $\begin{array}{l}\text { LV posterior } \\
\text { wall }(\mathrm{mm})\end{array}$ & $12.1 \pm 4.2$ & $10.6 \pm 2.2$ \\
\hline $\begin{array}{l}\text { LV ejection } \\
\text { fraction (\%) }\end{array}$ & $68.4 \pm 7.6$ & $68.6 \pm 7.7$ \\
\hline $\mathrm{E} / \mathrm{A}$ & $1.04 \pm 0.53$ & $1.21 \pm 0.30$ \\
\hline
\end{tabular}

$\mathrm{ACE}=$ angiotensin-converting enzyme; $\mathrm{LA}=$ left $\quad$ atrial; $\mathrm{LV}=$ left ventricular; $\mathrm{HCM}=$ hypertrophic cardiomyopathy.

${ }^{*} \mathrm{P}=0.02$ versus Controls.

$\dagger \mathrm{P}=0.0001$ versus Controls.

$(\mathrm{CT}){ }^{19}$ cardiovascular magnetic resonance (CMR) ${ }^{20}$ etc. have been used for evaluation of LA dimensions, volumes, and function. Recently, 3DSTE has been introduced, which encompasses benefits of STE and 3D echocardiography. 3DSTE uses different algorithm from RT3DE which is based on block matching of the myocardial speckles of the endocardial border during their frame-to-frame motion. ${ }^{21}$ Kleijn et al. ${ }^{9}$ have demonstrated that 3D echocardiography with direct volumetric (RT3DE) and speckle tracking methods (3DSTE) gives comparable and reproducible quantification of LV and LA volumes and function, making changeable application a viable option in daily clinical practice. Over assessment of LA volumetric and functional properties, 3DSTE seems to be reliable method for the accurate measurement of LV volumes respecting cardiac cycle. ${ }^{22-24}$ 3DSTE is also able to quantify regional and global LV myocardial deformation by strain analysis from a single data aquisition. $^{25-27}$ 3DSTE is a noninvasive tool for quantification of rotational and twist LV mechanics as well. ${ }^{28-30}$ Several calculated dyssynchrony parameters of the LV have been demonstrated by different authors. ${ }^{31-33}$ Some specific case report suggested its role in the evaluation of LA appendage $\mathrm{e}^{34}$ and quantification of right ventricular volumes ${ }^{35}$ and aortic root rotation ${ }^{36}$ etc. However, its clinical utility in the evaluation of the heart and large vessels is not fully described in the literature.

Increased volumes and impaired LA myocardial deformation are known features in $\mathrm{HCM}^{37}$ Moreover, occurrence of myocardial fibrosis in HCM was found to be associated with LA dysfunction. ${ }^{38}$ Abnormalities in strain theoretically could be due to chronically high LA pressures from diastolic dysfunction, LV outflow tract obstruction or higher grade MR, but intrinsic abnormalities including fibrosis of the LA wall should also be considered. However, further studies are warranted to examine whether relationship exists between dynamic obstruction and LA functional parameters detailed above. Moreover, the effect of alcohol septal ablation on these parameters could be also a subject of research.

\section{Limitation Section:}

The following important limitations should be taken into consideration:

(1) It is known that current image quality of 3DSTE is worse than that of 2D echocardiography due to low temporal and spatial image resolutions which could theoretically affect our results.

(2) 3DSTE seems to be feasible method for volumetric ${ }^{9,12}$ and strain $^{10,11}$ assessment of the LA. Despite the fact that several noninvasive tools (TDI, RT3DE, 2DSTE, CMR, CT, etc.) could be used to quantify LA volumes and function,, $15-20$ only limited number of studies are available, in which 3DSTE was compared to these widely used and accepted methodologies. ${ }^{9,12}$ Therefore, more comparative studies with other methods are warranted especially focusing on the limitations of 3DSTE.

(3) 3DSTE-derived strain parameters of healthy subjects were somewhat different from the results of previous studies. ${ }^{10,11}$ It could be explained by the fact that these parameters depend on the place of measurement (basal mid-superior regions etc.), even in healthy subjects. Moreover, the values are affected by the age, and other factors, as well. ${ }^{39}$ 


\section{TABLE III}

Comparison of 3DSTE-Derived Volumetric Left Atrial Parameters of Patients with Hypertrophic Cardiomyopathy and Controls

\begin{tabular}{|c|c|c|c|c|c|c|}
\hline & $\begin{array}{l}\text { Controls } \\
(n=23)\end{array}$ & $\begin{array}{l}\text { HCM Patients } \\
\quad(n=23)\end{array}$ & $\begin{array}{l}\text { HCM Patients with } \\
\text { Hypertension and/or } \\
\text { DM }(n=10)\end{array}$ & $\begin{array}{l}\text { HCM Patients } \\
\text { without } \\
\text { Hypertension and/ } \\
\text { or DM }(n=13)\end{array}$ & $\begin{array}{c}\text { HCM Patients } \\
\text { with } M R \geq 2(n=9)\end{array}$ & $\begin{array}{c}\text { HCM Patients } \\
\text { with } \mathrm{MR}<2 \\
(\mathrm{n}=14)\end{array}$ \\
\hline \multicolumn{7}{|c|}{ Calculated volumes } \\
\hline $\mathrm{V}_{\max }(\mathrm{mL})$ & $36.0 \pm 6.1$ & $66.4 \pm 20.4^{*}$ & $65.2 \pm 10.7^{*}$ & $67.2 \pm 26.0^{*}$ & $76.2 \pm 26.0^{*}$ & $59.0 \pm 13.3^{*}$ \\
\hline $\mathrm{V}_{\min }(\mathrm{mL})$ & $16.0 \pm 4.6$ & $39.2 \pm 19.1^{*}$ & $38.9 \pm 14.1^{*}$ & $39.4 \pm 22.7^{*}$ & $46.6 \pm 23.8^{* *}$ & $32.7 \pm 13.3^{*}$ \\
\hline $\mathrm{V}_{\text {preA }}(\mathrm{mL})$ & $24.0 \pm 6.2$ & $53.6 \pm 19.9^{*}$ & $54.0 \pm 12.6^{*}$ & $53.3 \pm 24.5^{*}$ & $64.1 \pm 22.4^{* *}$ & $45.3 \pm 14.7^{*}$ \\
\hline \multicolumn{7}{|c|}{ Stroke volumes } \\
\hline TASV $(\mathrm{mL})$ & $20.0 \pm 4.6$ & $27.2 \pm 9.7^{\dagger}$ & $26.3 \pm 11.4^{\dagger}$ & $27.8 \pm 8.5^{\dagger}$ & $26.6 \pm 10.0^{\dagger}$ & $26.3 \pm 9.5^{\dagger}$ \\
\hline PASV $(\mathrm{mL})$ & $12.0 \pm 4.6$ & $12.8 \pm 8.6$ & $11.2 \pm 10.8$ & $13.9 \pm 6.6$ & $12.1 \pm 7.3$ & $14.3 \pm 9.1$ \\
\hline AASV (mL) & $8.0 \pm 3.2$ & $14.4 \pm 8.1^{\dagger}$ & $15.0 \pm 10.5^{\dagger}$ & $13.9 \pm 6.0^{\dagger}$ & $17.4 \pm 9.4^{\dagger}$ & $12.6 \pm 6.8^{\dagger}$ \\
\hline \multicolumn{7}{|c|}{ Emptying fractions } \\
\hline TAEF (\%) & $55.3 \pm 9.8$ & $42.8 \pm 15.5^{\dagger}$ & $40.8 \pm 16.9^{\dagger}$ & $44.3 \pm 14.8^{\dagger}$ & $41.1 \pm 14.9^{\dagger *}$ & $45.6 \pm 15.6^{\dagger}$ \\
\hline PAEF (\%) & $33.5 \pm 11.6$ & $19.9 \pm 14.5^{\dagger}$ & $16.8 \pm 16.1^{\dagger}$ & $22.2 \pm 13.1^{\dagger}$ & $15.7 \pm 9.3^{\dagger}$ & $23.6 \pm 16.9^{\dagger}$ \\
\hline AAEF (\%) & $33.3 \pm 9.5$ & $28.6 \pm 14.3$ & $27.8 \pm 17.6$ & $29.3 \pm 11.9$ & $29.4 \pm 17.3$ & $29.0 \pm 12.5$ \\
\hline
\end{tabular}

$\mathrm{V}_{\max }=$ maximum left atrial volume; $\mathrm{V}_{\min }=$ minimum left atrial volume; $\mathrm{V}_{\mathrm{preA}}=$ left atrial volume before atrial contraction; $\mathrm{TASV}=$ total atrial stroke volume; $\mathrm{TAEF}=$ total atrial emptying fraction; $\mathrm{AASV}=$ active atrial stroke volume; $\mathrm{AAEF}=\mathrm{active}$ atrial emptying fraction; PASV = passive atrial stroke volume; PAEF = passive atrial emptying fraction; $D M=$ diabetes mellitus; $\mathrm{HCM}=$ hypertrophic cardiomyopathy; $\mathrm{MR}=$ mitral regurgitation; STE = speckle tracking echocardiography; $3 \mathrm{D}=$ three-dimensional.

${ }^{*} \mathrm{p}<0.0001$ versus controls.

${ }^{\dagger} \mathrm{p}<0.05$ versus controls.

$\mathrm{A}<0.05$ versus $\mathrm{HCM}$ patients with $\mathrm{MR}<2$.

\section{TABLE IV}

Comparison of 3DSTE-Derived Left Atrial Strain Parameters of Patients with Hypertrophic Cardiomyopathy and Controls

\begin{tabular}{|c|c|c|c|c|c|c|}
\hline & $\begin{array}{l}\text { Controls } \\
(n=23)\end{array}$ & $\begin{array}{c}\text { HCM } \\
\text { Patients } \\
(n=23)\end{array}$ & $\begin{array}{c}\text { HCM Patients } \\
\text { with Hypertension } \\
\text { and/or } \\
\operatorname{DM}(\mathrm{n}=10)\end{array}$ & $\begin{array}{c}\text { HCM Patients } \\
\text { without } \\
\text { Hypertension } \\
\text { and/or DM }(n=13)\end{array}$ & $\begin{array}{l}\text { HCM Patients } \\
\text { with } \mathrm{MR} \geq 2 \\
(\mathrm{n}=9)\end{array}$ & $\begin{array}{c}\text { HCM Patients } \\
\text { with } \mathrm{MR}<2 \\
(\mathrm{n}=14)\end{array}$ \\
\hline \multicolumn{7}{|l|}{ Global strains } \\
\hline Radial strain (\%) & $-19.6 \pm 11.7$ & $-12.2 \pm 6.7^{*}$ & $-14.5 \pm 8.5$ & $-10.4 \pm 4.4^{*}$ & $-12.1 \pm 5.8$ & $-12.3 \pm 7.4^{\dagger}$ \\
\hline $\begin{array}{l}\text { Circumferential } \\
\text { strain (\%) }\end{array}$ & $29.8 \pm 12.1$ & $26.5 \pm 16.5$ & $26.4 \pm 19.1$ & $26.6 \pm 15.0$ & $25.3 \pm 15.9$ & $27.2 \pm 17.4$ \\
\hline $\begin{array}{l}\text { Longitudinal } \\
\text { strain (\%) }\end{array}$ & $23.9 \pm 6.3$ & $18.0 \pm 7.4^{*}$ & $18.0 \pm 6.8^{\dagger}$ & $18.0 \pm 8.1^{\dagger}$ & $15.8 \pm 6.4^{*}$ & $19.4 \pm 7.9$ \\
\hline 3D strain (\%) & $-12.5 \pm 10.2$ & $-6.1 \pm 4.4^{*}$ & $-7.9 \pm 5.1$ & $-4.7 \pm 3.3^{*}$ & $-6.6 \pm 4.8$ & $-5.8 \pm 4.2^{\dagger}$ \\
\hline Area strain (\%) & $59.0 \pm 19.1$ & $49.3 \pm 27.8$ & $51.0 \pm 31.2$ & $48.0 \pm 26.2$ & $44.4 \pm 27.3$ & $52.3 \pm 28.7$ \\
\hline \multicolumn{7}{|c|}{ Mean segmental strains } \\
\hline Radial strain (\%) & $-23.7 \pm 11.5$ & $-16.3 \pm 10.7^{\dagger}$ & $-18.6 \pm 8.6$ & $-14.6 \pm 3.2^{*}$ & $-16.2 \pm 5.7$ & $-16.4 \pm 6.9^{\dagger}$ \\
\hline $\begin{array}{l}\text { Circumferential } \\
\text { strain (\%) }\end{array}$ & $38.6 \pm 23.5$ & $29.9 \pm 18.2$ & $31.3 \pm 17.9$ & $28.8 \pm 15.1$ & $26.8 \pm 17.1$ & $31.9 \pm 15.6$ \\
\hline $\begin{array}{l}\text { Longitudinal } \\
\text { strain (\%) }\end{array}$ & $30.6 \pm 17.7$ & $20.1 \pm 12.4^{\dagger}$ & $20.5 \pm 6.1$ & $19.7 \pm 7.9^{\dagger}$ & $17.9 \pm 5.9^{\dagger}$ & $21.4 \pm 7.6$ \\
\hline 3D strain (\%) & $-17.0 \pm 9.5$ & $-10.7 \pm 8.3^{\dagger}$ & $-12.3 \pm 5.8$ & $-9.4 \pm 2.5^{*}$ & $-11.0 \pm 4.3$ & $-10.5 \pm 4.6^{\dagger}$ \\
\hline Area strain (\%) & $75.9 \pm 41.7$ & $54.1 \pm 33.2^{\dagger}$ & $56.4 \pm 32.2$ & $52.4 \pm 26.3$ & $49.4 \pm 29.5$ & $57.1 \pm 28.3$ \\
\hline
\end{tabular}

$\mathrm{DM}$ = diabetes mellitus; $\mathrm{HCM}$ = hypertrophic cardiomyopathy; $\mathrm{MR}=$ mitral regurgitation; $\mathrm{STE}$ = speckle tracking echocardiography; $3 \mathrm{D}=$ three-dimensional.

$* \mathrm{P}<0.01$ versus Controls.

${ }^{\dagger} \mathrm{P}<0.05$ versus Controls.

$\mathrm{P}<0.05$ versus $\mathrm{HCM}$ patients with $\mathrm{MR}<2$.

(4) Despite the fact that LA appendage could be analyzed by modern transthoracic echocardiographic methodologies including
$\mathrm{TDI}^{40,41} 3$ 3DSTE $^{34}$ etc., LA appendage and pulmonary veins were excluded from evaluations. 
(5) There are several aspects of HCM including genetic background, history of embolism, development of arrhythmias, etc., their relationship with the LA dysfunction was not examined in this study.

(6) The effects of dynamic obstructions on LA functional parameters were not examined in this study.

(7) LA function deteriorated in patients with sick sinus syndrome and in those with paroxysmal atrial fibrillation. ${ }^{11}$ However, all of our patients and controls were in sinus rhythm.

(8) This was a single-center experience and limited by a relatively small number of $\mathrm{HCM}$ patients. Caution should be taken when interpreting the results.

\section{Conclusions:}

Three-dimensional STE allows evaluation of LA (dys) function by volumetric and strain analysis in HCM. There is an opportunity of detailed assessment of LA dysfunction in various forms of structural and functional heart disease.

Acknowledgment: Dr. Attila Nemes holds a János Bolyai Research Fellowship (Budapest, Hungary).

\section{References}

1. Maron BJ: Hypertrophic cardiomyopathy: A systematic review. JAMA 2002;287:1308-1320.

2. Roșca M, Popescu BA, Beladan CC, et al: Left atrial dysfunction as a correlate of heart failure symptoms in hypertrophic cardiomyopathy. I Am Soc Echocardiogr 2010;23:1090-1098.

3. Anwar AM, Soliman OI, Nemes A, et al: An integrated approach to determine left atrial volume, mass and function in hypertrophic cardiomyopathy by two-dimensional echocardiography. Int J Cardiovasc Imaging 2008;24: 45-52.

4. Yang H, Woo A, Monakier D, et al: Enlarged left atrial volume in hypertrophic cardiomyopathy: A marker for disease severity. I Am Soc Echocardiogr 2005;18:10741082.

5. Saura D, Marín F, Climent V, et al: Left atrial remodelling in hypertrophic cardiomyopathy: Relation with exercise capacity and biochemical markers of tissue strain and remodelling. Int / Clin Pract 2009;63:1465-1471.

6. Girasis C, Vassilikos V, Efthimiadis GK, et al: Patients with hypertrophic cardiomyopathy at risk for paroxysmal atrial fibrillation: Advanced echocardiographic evaluation of the left atrium combined with non-invasive P-wave analysis. Eur Heart / Cardiovasc Imaging 2013;14:425434.

7. Hoit BD, Shao Y, Gabel M, et al: In vivo assessment of left atrial contractile performance in normal and pathological conditions using a time-varying elastance model. Circulation 1994;89:1829-1838.

8. Urbano-Moral JA, Patel AR, Maron MS, et al: Threedimensional speckle-tracking echocardiography: Methodological aspects and clinical potential. Echocardiography 2012;29:997-1010.

9. Kleijn SA, Aly MF, Terwee CB, et al: Comparison between direct volumetric and speckle tracking methodologies for left ventricular and left atrial chamber quantification by three-dimensional echocardiography. $\mathrm{Am} /$ Cardiol 2011;108:1038-1044.

10. Mochizuki A, Yuda S, Oi Y, et al: Assessment of left atrial deformation and synchrony by three-dimensional speckle-tracking echocardiography: Comparative studies in healthy subjects and patients with atrial fibrillation. J Am Soc Echocardiogr 2013;26:165-174.

11. Chadaide S, Domsik P, Kalapos A, et al: Three-Dimensional Speckle Tracking Echocardiography-Derived Left Atrial Strain Parameters Are Reduced in Patients with Atrial Fibrillation (Results from the MAGYAR-Path Study). Echocardiography 2013;30:1078-1083.

12. Nemes A, Domsik P, Kalapos A, et al: Comparison of three-dimensional speckle tracking echocardiography and two-dimensional echocardiography for evaluation of left atrial size and function in healthy volunteers (Results from the MAGYAR-Healthy Study). Echocardiography 2013 Dec 17 [Epub ahead of print].

13. Maron BJ, McKenna WJ, Danielson GK, et al: Task Force on Clinical Expert Consensus Documents. American College of Cardiology; Committee for Practice Guidelines. European Society of Cardiology. American College of Cardiology/European Society of Cardiology clinical expert consensus document on hypertrophic cardiomyopathy. A report of the American College of Cardiology Foundation Task Force on Clinical Expert Consensus Documents and the European Society of Cardiology Committee for Practice Guidelines. I Am Coll Cardiol 2003;42:1687-1713.

14. World Medical Association Declaration of Helsinki. Ethical Principles for Medical Research Involving Human Subjects. http://www.wma.net/en/30publications/10policies/b3/index.html

15. Anwar AM, Soliman OI, Geleijnse ML, et al: Assessment of left atrial volume and function by real-time threedimensional echocardiography. Int / Cardiol 2008;123: 155-161.

16. Khankirawatana B, Khankirawatana S, Porter T: How should left atrial size be reported? Comparative assessment with use of multiple echocardiographic methods. Am Heart / 2004;147:369-374.

17. Lang RM, Bierig M, Devereux RB, et al: Chamber Quantification Writing Group; American Society of Echocardiography's Guidelines and Standards Committee; European Association of Echocardiography. Recommendations for chamber quantification: A report from the American Society of Echocardiography's Guidelines and Standards Committee and the Chamber Quantification Writing Group, developed in conjunction with the European Association of Echocardiography, a branch of the European Society of Cardiology. I Am Soc Echocardiogr 2005;18:1440-1463.

18. Paraskevaidis IA, Panou F, Papadopoulos C, et al: Evaluation of left atrial longitudinal function in patients with hypertrophic cardiomyopathy: A tissue Doppler imaging and twodimensional strain study. Heart 2009;95:483-489.

19. Kircher B, Abbott JA, Pau S, et al: Left atrial volume determination by biplane two-dimensional echocardiography: Validation by cine computed tomography. Am Heart I 1991;121(3 Pt 1):864-871.

20. Papavassiliu T, Germans T, Flüchter $S$, et al: CMR findings in patients with hypertrophic cardiomyopathy and atrial fibrillation. J Cardiovasc Magn Reson 2009;11:34.

21. Nemes A, Kalapos A, Domsik P, et al: Three-dimensional speckle-tracking echocardiography - a further step in the non-invasive three-dimensional cardiac imaging. Orv Hetil 2012;153:1570-1577.

22. Nesser HJ, Mor-Avi V, Gorissen W, et al: Quantification of left ventricular volumes using three-dimensional echocardiographic speckle tracking: Comparison with MRI. Eur Heart J 2009;30:1565-1573. 
23. Kleijn SA, Brouwer WP, Aly MF, et al: Comparison between three-dimensional speckle-tracking echocardiography and cardiac magnetic resonance imaging for quantification of left ventricular volumes and function. Eur Heart J Cardiovasc Imaging 2012;13:834-839.

24. Kleijn SA, Aly MF, Terwee CB, et al: Reliability of left ventricular volumes and function measurements using three-dimensional speckle tracking echocardiography. Eur Heart J Cardiovasc Imaging 2012;13:159-168.

25. Saito K, Okura H, Watanabe N, et al: Comprehensive evaluation of left ventricular strain using speckle tracking echocardiography in normal adults: Comparison of three-dimensional and two-dimensional approaches. I Am Soc Echocardiogr 2009;22:1025-1030.

26. Seo $Y$, Ishizu T, Enomoto $Y$, et al: Validation of 3-dimensional speckle tracking imaging to quantify regional myocardial deformation. Circ Cardiovasc Imaging 2009; 2:451-459.

27. Maffessanti F, Nesser HJ, Weinert L, et al: Quantitative evaluation of regional left ventricular function using three-dimensional speckle tracking echocardiography in patients with and without heart disease. $\mathrm{Am} / \mathrm{Cardiol}$ 2009;104:1755-1762.

28. Zhou Z, Ashraf M, Hu D, et al: Three-dimensional speckletracking imaging for left ventricular rotation measurement: An in vitro validation study. I Ultrasound Med 2010;29:903-909.

29. Andrade J, Cortez LD, Campos O, et al: Left ventricular twist: Comparison between two- and three-dimensional speckle tracking echocardiography in healthy volunteers. Eur J Echocardiogr 2011;12:76-79.

30. Ashraf M, Zhou Z, Nguyen T, et al: Apex to base left ventricular twist mechanics computed from high frame rate two-dimensional and three-dimensional echocardiography: A comparison study. I Am Soc Echocardiogr 2012; 25:121-128.

31. Tanaka H, Hara H, Saba S, et al: Usefulness of three-dimensional speckle tracking strain to quantify dyssynchrony and the site of latest mechanical activation. Am J Cardiol 2010;105:235-242.

32. Li CH, Carreras F, Leta R, et al: Mechanical left ventricular dyssynchrony detection by endocardium displacement analysis with 3D speckle tracking technology. Int J Cardiovasc Imaging 2010;26:867-870.

33. Tatsumi K, Tanaka H, Tsuji T, et al: Strain dyssynchrony index determined by three-dimensional speckle area tracking can predict response to cardiac resynchronization therapy. Cardiovasc Ultrasound 2011;9:11.

34. Nemes A, Domsik P, Kalapos A, et al: Visualization of left atrial appendage by three-dimensional speckle-tracking echocardiography: A case from the MAGYAR-Path Study. Herz 2013 Jul 25 [Epub ahead of print].

35. Nemes A, Domsik P, Kalapos A, et al: Can aortic root rotation be quantified by three-dimensional speckletracking echocardiography? (from the MAGYAR-Healthy Study). Int / Cardiol 2013;168:5008-5010.

36. Domsik P, Kalapos A, Katona M, et al: Demonstration of right ventricular volume assessment by three-dimensional speckle-tracking echocardiography in an infant with surgically palliated hypoplastic left heart syndrome (a case from the MAGYAR-Path Study). Echocardiography 2013; 30:E59-E60.

37. Gabrielli L, Enriquez A, Cordova S, et al: Assessment of left atrial function in hypertrophic cardiomyopathy and athlete's heart: A left atrial myocardial deformation study. Echocardiography 2012;29:943-949.

38. Prinz $C$, van Buuren $F$, Bogunovic $N$, et al: In patients with hypertrophic cardiomyopathy myocardial fibrosis is associated with both left ventricular and left atrial dysfunction. Acta Cardiol 2012;67:187-193.

39. Xia J, Gao Y, Wang Q, et al: Left atrial function examination of healthy individuals with 2D speckle-tracking imaging. Exp Ther Med 2013;5:243-246.

40. Uretsky S, Shah A, Bangalore S, et al: Assessment of left atrial appendage function with transthoracic tissue Doppler echocardiography. Eur J Echocardiogr 2009; 10:363-371.

41. Yoshida $N$, Okamoto $M$, Hirao $H$, et al: High plasma human atrial natriuretic peptide and reduced transthoracic left atrial appendage wall-motion velocity are noninvasive surrogate markers for assessing thrombogenesis in patients with paroxysmal atrial fibrillation. Echocardiography 2014;31:965-971. 